\title{
MUDANÇAS DO MARCO INSTITUCIONAL DA EDUCAÇÃO PROFISSIONAL: UMA LEITURA A PARTIR DOS DADOS DO CENSO ESCOLAR
}

\author{
Remi Castioni* \\ Maria Célia Costa Andrade**
}

\section{Resumo}

Este trabalho discute o impacto das mudanças introduzidas no marco legal da educação profissional, particularmente com o advento do Decreto $\mathrm{n}^{\circ}$ $5.154 / 2004$, em termos de oferta de vagas pelas redes federal, estadual e particular. O objetivo é seguir o comportamento dos dados do Censo Escolar e analisar se estaria havendo um aumento na oferta dessa modalidade de ensino ou se isso é mero efeito de acomodação das redes, em observância ao que preceitua o marco legal. Infere-se também que uma possível ampliação de ofertas pode estar ocorrendo por mero efeito estatístico por conta da melhor remuneração das matrículas do ensino médio integrado à educação profissional na conta do Fundeb - Fundo de Manutenção e Desenvolvimento da Educação Básica e de Valorização dos Profissionais da Educação. Por fim, se discutem os rumos do ensino médio, elo frágil entre o final do ensino fundamental e o ensino superior.

Palavras-chave: Educação profissional. Censo escolar. Ensino médio integrado. Rede federal.

\section{Introdução}

As políticas públicas de educação têm sido objeto de comparação das iniciativas conduzidas pelo governo Fernando Henrique Cardoso - FHC e pelo atual governo Lula. As medidas adotadas por ambos os governos foram objeto de intenso debate no auge da campanha eleitoral de 2006 e continuam a

\footnotetext{
* Doutor em Educação pela Universidade Estadual de Campinas, Brasil (2002). Professor do Departamento de Planejamento e Administração da Faculdade de Educação da Universidade de Brasília (rcastioni@globo.com).

** Socióloga. Consultora do Programa das Nações Unidas para o Desenvolvimento (PNUD). Atuou no Ministério da Educação (MEC) entre os anos de 2002 a 2007 (mceldf@terra.com.br).
} 
ser feitas a cada divulgação de resultados das pesquisas educacionais conduzidas pelo Ministério da Educação - MEC. Entre as diversas iniciativas protagonizadas por esses dois governos figura o tema da educação profissional como importante ponto de inflexão de ambos os lados. O governo de FHC atribui a si o fato de ter colocado o tema da educação profissional na agenda da sociedade ao permitir uma expansão nas regiões onde havia carência de oferta. O governo Lula, ao contrário, afirma que a verdadeira expansão está sendo feita agora quando se completa o primeiro centenário das escolas técnicas.

O objetivo deste texto é o de problematizar a questão da oferta de educação profissional de nível técnico nos últimos anos a partir da mudança do marco legal e sua repercussão nos censos escolares. O percurso foi analisar os dados divulgados pelo Instituto Nacional de Estudos e Pesquisas Educacionais Anísio Teixeira - Inep, apresentados de forma consolidada na publicação Educação Profissional Técnica de Nível Médio no Censo Escolar, lançado em setembro de 2006, que traz uma análise do desenvolvimento da educação profissional de nível médio, no período de 2003 a 2005, com base nas informações dos Censos Escolares. A partir desses dados, embora não comparáveis, cotejar com os recentes dados divulgados no Censo Escolar de 2008. Os dados populacionais por faixa etária e nível de escolaridade foram obtidos da Pesquisa Nacional por Amostra de Domicílios - PNAD, do IBGE.

Antes de iniciarmos a problematização, é importante registrarmos a voracidade empreendida em ambos os governos no que se refere ao marco legal da educação profissional. Os oito anos que antecederam o atual governo produziram mudanças significativas na educação brasileira (MARQUES, 2004), em particular, na modalidade de educação profissional. Desde a publicação da LDB, em 1996, que introduziu um capítulo sobre educação profissional, a emergência do Decreto $\mathrm{n}^{\circ} 2.208$, de 17 de abril de 1997, que separou as matrículas do ensino médio do nível técnico, as diretrizes curriculares para a educação profissional e os parâmetros curriculares por área da atividade econômica e a atração de um empréstimo internacional de U\$ 500 milhões $^{1}$ mostraram uma disposição do governo FHC em regulamentar a área da educação profissional. As mudanças introduzidas geraram intenso debate entre os estudiosos do assunto. As principais referências a essas mudanças na educação profissional podem ser obtidas em Carvalho (2003), Cunha (2000a), Ferreti

1. Na realidade, o valor do empréstimo internacional foi de U\$250 milhões, do Banco Interamericano de Desenvolvimento - BID; os outros U\$ 250 milhões seriam da contrapartida nacional, sendo U\$ 125 do Tesouro Nacional e U\$ 125 do Fundo de Amparo ao Trabalhador - FAT. Em 2005, o valor do empréstimo foi reduzido para U\$ 220 milhões, sendo metade para a contrapartida local e a outra do empréstimo internacional. 
(1997), Kuenzer (1997), Lima Filho (2003), Zibas (2002). Não é nossa pretensão retomar esse debate, apenas para situar que as origens da reforma basearamse em trabalhos de brasileiros que trabalharam em organismos internacionais, inclusive o próprio Ministro da Educação, Paulo Renato Souza, quando da sua passagem pelo Banco Interamericano de Desenvolvimento - BID entre 1992 e 1993. As principais referências à contribuição e justificativas da reforma podem ser encontradas em Castro (1997, 1999, 2003 e 2005).

Se destacamos a intensidade das reformas introduzidas no governo FHC na área da educação profissional, neste, as iniciativas não foram de menor volume. A Secretaria de Educação Profissional e Tecnológica - Setec² ${ }^{2}$ do Ministério da Educação, tem empreendido nos últimos anos importantes iniciativas com o objetivo de elevar o número de matrículas da educação profissional de nível técnico e tecnológico no País, removendo, na justificativa governamental, os entraves existentes. A principal iniciativa foi, sem dúvida, o Decreto $\mathrm{n}^{\circ} 5.154$, de 23 de julho de 2004, que permitiu novamente ofertar a modalidade de ensino médio integrado ao ensino técnico, limitação essa que vigia há sete anos e havia sido instituída pelo Decreto $\mathrm{n}^{\circ} 2.208$, de 17 de abril de 1997. O novo decreto também criou três níveis de classificação no que se refere à educação profissional: i - formação inicial e continuada de trabalhadores; ii - educação profissional técnica de nível médio; e iii - educação profissional tecnológica de graduação.

O Decreto $\mathrm{n}^{\circ} 5.224$, de $1^{\circ}$ de outubro de 2004, dispôs sobre a estrutura e organização dos Centros Federais de Educação Tecnológica - Cefet e também sobre a oferta de educação tecnológica e de educação de nível técnico e de formação inicial e continuada de trabalhadores. A regulamentação dos Cefets originou-se ainda em 1978, quando foram criados os primeiros Cefets, e prosseguiu até a Lei n ${ }^{\circ} 8.948$, de 8 de dezembro de 1994, quando praticamente todas as Escolas Técnicas Federais foram cefetizadas, com exceção da Escola Técnica Federal de Palmas-TO. O Decreto n ${ }^{\circ}$ 5.478, de 24 de Junho de 2005, instituiu no âmbito das instituições federais de educação tecnológica o Programa de Integração da Educação Profissional ao Ensino Médio na Modalidade de Educação de Jovens e Adultos - Proeja. Posteriormente esse Decreto foi revogado pelo Decreto $\mathrm{n}^{\circ}$ 5.840, de 13 de Julho de 2006, que ampliou o

2. A Setec foi criada em 2004 ao perder o "M" do ensino médio para a Secretaria de Educação Básica SEB. A área do ensino médio, antes na então Semtec, foi transformada em departamento na estrutura da atual SEB. A atual Setec manteve na sua jurisdição apenas a rede federal de ensino. Também uma das importantes medidas foi a de transferir ao FNDE a gestão do Programa de Expansão da Educação Profissional - Proep, principal projeto da Setec. Entre as atribuições da atual secretaria está a de coordenar a rede federal e executar alguns projetos especiais, como Escola de Fábrica, além de propor políticas para a área de educação profissional, como recentemente fez com o Proeja. 
Proeja, permitindo que qualquer sistema de ensino possa ofertá-lo em acréscimo ao que previa o Decreto $\mathrm{n}^{\circ} 5.478 / 2005$, que limitava apenas à rede federal essa oferta ${ }^{3}$.

A Lei $\mathrm{n}^{\circ}$ 11.180, de 23 de setembro de 2005, criou o Projeto Escola de Fábrica, modalidade que prevê a concessão de bolsas de permanência a estudantes inseridos numa atividade de aprendizagem tendo como locus um espaço produtivo, e para tanto se alteraram, inclusive, os artigos 428 e 433 da Consolidação das Leis do Trabalho - CLT, aprovada pelo Decreto-Lei n ${ }^{\circ} 5.452$, de $1^{\circ}$ de maio de 1943, no que se refere ao trabalho do menor-aprendiz.

Houve a criação da Universidade Tecnológica Federal do Paraná, por meio da Lei $\mathrm{n}^{\circ}$ 11.184, de 7 de outubro de 2005, em substituição ao Centro Federal de Educação Tecnológica do Paraná. A Lei no 11.195, de 18 de novembro de 2005, permitiu a expansão da rede federal de educação técnica e tecnológica, limitada havia mais de 10 anos por ocasião do $\S 5^{\circ}$ do artigo $3^{\circ}$ da Lei ${ }^{\circ} 8.948$, de 8 de dezembro de 1994, que expressamente vetava qualquer iniciativa nesse sentido a não ser que fosse em parcerias com outros entes federados ou com organizações sociais e cuja manutenção também estaria a cargo deles. Importante também foi a Resolução $n^{\circ} 1$, de 3 de fevereiro de 2005, do Conselho Nacional de Educação, que atualizou as Diretrizes Curriculares Nacionais para o Ensino Médio e para a Educação Profissional Técnica de Nível Médio às disposições do Decreto n ${ }^{\circ}$ 5.154/ 2004.

As mudanças prosseguiram nos anos seguintes, e destacamos, entre elas, o Decreto $\mathrm{n}^{\circ} 6.095$, de 24 de abril de 2007, que estabelece regras para a constituição dos Institutos Federais de Educação, Ciência e Tecnologia - Ifets, no âmbito da Rede Federal de Educação Tecnológica, e posteriormente a própria Lei $\mathrm{n}^{\circ}$ 11.892, de 29 de dezembro de 2008, que institui a Rede Federal de Educação Profissional, Científica e Tecnológica e cria os Institutos Federais de Educação, Ciência e Tecnologia - Ifets. Da então rede federal, o MEC só não conseguiu a adesão da Universidade Tecnológica Federal do Paraná - UTFPR, por já estar em um patamar superior ao dos institutos, e dos Centros Federais de Educação Tecnológica Celso Suckow da Fonseca - Cefet-RJ e de Minas Gerais - Cefet-MG, que travam uma batalha no Legislativo para alcançarem o status dos paranaenses. Além dessas iniciativas, merece destaque o Decreto $\mathrm{n}^{\circ}$ 6.301, de 12 de dezembro de 2007, que instituiu o Sistema Escola Técnica Aberta do Brasil - e-Tec Brasil; e o Decreto $n^{\circ}$ 6.302, de 12 de dezembro de 2007, que institui o Programa Brasil Profissionalizado, uma estratégia voltada para as redes estaduais de ensino, visando à oferta de ensino médio articulada com a educação profissional nos estados.

3. Para uma resenha da legislação, consultar Christophe (2005). 
O Congresso Nacional aprovou também o Projeto de Lei n ${ }^{\circ}$ 919, de 30 de abril de 2007, de iniciativa do MEC, que muda a Lei de Diretrizes e Bases LDB nos artigos 37, e que trata da Educação de Jovens e Adultos, e os artigos 39 a 42 da LDB, que tratam da educação profissional e que estavam intactos desde a sua promulgação (Lei $n^{\circ} 9.394$ de 20 de dezembro de 1996). Particularmente, na Educação de Jovens e Adultos, o artigo 37 da LDB introduz um novo parágrafo, o terceiro, que disciplina que a educação de jovens e adultos deve articular-se, preferencialmente, com a educação profissional. O capítulo da educação profissional passa a se chamar "educação profissional e tecnológica" e incorpora quase tudo o que foi introduzido com o Decreto n ${ }^{\circ} 5.154$, no que se refere às formas de oferta da educação profissional. O Projeto foi transformado na Lei $n^{\circ} 11.741$, de 16 de julho de 2008.

Como podemos observar, foram volumosas nesse governo as iniciativas no campo da educação profissional, que não diferem em quantidade e impactam da mesma maneira que impactaram as reformas anteriormente introduzidas pelo governo FHC. Entretanto, como bem assinalaram Frigotto et al. (2005), as mudanças introduzidas não apontam um rumo e caracterizam-se como um feixe de iniciativas que não se coadunam. Na visão dos autores, não estariam ocorrendo iniciativas que contribuíssem para a constituição de um sistema ou subsistema de educação profissional. Em Frigotto (2003) também essa preocupação era presente quando da realização de um seminário em junho de 2003, em Brasília, que teve o objetivo de dar um novo rumo à educação profissional. Os autores ${ }^{4}$ que colaboraram na integração de ações no campo da educação profissional mostram-se preocupados com as iniciativas tomadas pelos atuais dirigentes do MEC sem uma perspectiva de coordenação e de rumo. Posteriormente àquele seminário, os autores chegaram a formular importante reflexão sobre o lugar do "trabalho" no currículo do ensino médio ao criticarem a visão até então empreendida que revela "[...] a dificuldade de lidar com o trabalho no seu sentido formativo, criador de cultura e aperfeiçoamento do ser humano, que supere as relações de exploração e geração de pobreza [...]" (FRIGOTTO et al., 2004, p. 13).

A preocupação dos autores é reforçada pelo recente embate envolvendo o Sistema S, onde o governo tentou dobrar a estrutura do sistema na forma de alocação dos recursos com os atuais $60 \%$ para assistência social e $40 \%$ para a aprendizagem sendo invertidos, mas contentou-se com o aumento gradativo

4. Gaudêncio Frigotto e Maria Ciavatta, que assinam o texto juntamente com Marise Nogueira Ramos atuaram na organização do texto-base do referido Seminário: concepções, experiências, problemas e propostas. Marise Ramos, inclusive, chegou a ser Diretora de Ensino Médio da então Semtec na gestão do secretário Antônio Ibañez Ruiz, atualmente na Câmara de Educação Básica do Conselho Nacional de Educação CNE. 
de vagas em cursos gratuitos de forma escalonada vinculada a uma aplicação de recursos que pode chegar a $2 / 3$ da receita. No entanto, não há certeza se a matriz de fato será invertida. No auge da discussão, o presidente da Confederação Nacional da Indústria (CNI), deputado Armando Monteiro (PTB$\mathrm{PE})$, mandou o seguinte recado: “O sistema não foi criado para ser política pública" ${ }^{5}$.

Isso demonstra que a idéia de organizar um sistema de educação profissional é algo ainda distante, e de fato é curioso que o governo que repassa $\mathrm{R} \$$ 8 bilhões ao ano às entidades empresariais via Guia da Previdência Social GPS, não consiga fazer com que esse sistema se integre minimamente a um sistema público de educação profissional. Também curioso é o fato de o governo federal, numa tentativa de participar da gestão do Sistema $S$, publicar três decretos $(5.725,5.726$ e 5.727, de 16 de março de 2006) que introduzem na gestão do sistema $S$ representantes de centrais sindicais e ampliam a presença de mais dois membros do Poder Executivo Federal. A legislação atual já previa representantes dos trabalhadores e dos Ministérios envolvidos na gestão dos recursos (Previdência e Trabalho), Ministérios estes que têm o poder de aprovar ou vetar o orçamento das respectivas entidades, e nem por isso o Sistema $S$ agiu de forma diferente do que costuma fazer desde a sua fundação pelo Decreto-Lei n ${ }^{\circ} 4.048$, de 22 de janeiro de 1942, no caso do Senai. O governo garante assento no Conselho de Administração do Sistema $S$ às centrais sindicais, mas não dá esse mesmo status ao Ministério da Educação. De fato, a resposta mais apropriada a isso pode ser encontrada no documento do Ipea (2006, p. 183), que qualificou as ações de educação profissional mobilizadas por uma ampla rede com recursos públicos em um não-sistema:

Pode-se, em princípio, entender esse conjunto como um não-sistema invisível. É um não-sistema por se tratar de uma coleção desconexa e heterogênea de instituições e cursos, enlaçados em tramas informais e paralelas, mas raramente orientadas por uma visão de conjunto do próprio segmento ou por políticas públicas. É invisível para fins de estatísticas oficiais e políticas públicas, ainda que suas principais agências operem há mais de 60 anos. (grifado no original).

Voltando a nossa proposta original, a questão principal é que resultados estariam sendo gerados por essa nova "voracidade" no campo da educação profissional. Os dados a seguir mostram o desempenho das matrículas nos primeiros anos da nova fase regulamentatória. Uma questão importante é de que a legislação no governo Lula não impediu as modalidades de ensino médio e ensino técnico previstas pelo governo $\mathrm{FHC}$, ou seja, a concomitância

5. O Valor Econômico, 5 de maio de 2008. 
e a subsequência, apenas permitiu a integração ao ensino médio, inclusive com matrícula única, sendo que pelo Decreto n ${ }^{\circ}$ 2.208/1997 eram separadas. Segundo esse decreto, os alunos somente poderiam cursar o ensino técnico ao longo do ensino médio, mas somente obteriam o título quando o concluíssem. Um dos principais efeitos da separação do ensino médio do ensino técnico foi o "envelhecimento" das matrículas do ensino técnico. Em 1990, no Estado de São Paulo, aproximadamente 40\% dos alunos matriculados no antigo $2^{\circ}$ grau faziam algum curso técnico. Em 1999, essa relação atingiu $9 \%$. Como o ensino médio em São Paulo dobrou o número de matrículas nesse mesmo período, de 1 milhão para 2 milhões, tem-se que o ensino técnico, após as reformas, apresentou uma perda de atração sobre o seu principal público: os alunos e concluintes do ensino médio, ou seja, os jovens.

Os dados do Centro Paula Sousa (CASTIONI, 2008, p. 131) mostram que a faixa etária acima de 27 anos, que não tinha matrículas em 1995, passou a representar 16\% em 1999, dois anos após a separação dos ensinos médio e técnico, enquanto que a faixa etária dos 15 a 17 anos reduziu sua participação no mesmo período de $83 \%$ para $22 \%$, e a faixa etária dos 18 aos 27 anos teve aumentada sua participação de $17 \%$ para $62 \%$. Isso revela que muitos trabalhadores com ensino médio retornaram à escola, criando um distanciamento ainda maior com aqueles que continuam com baixa escolaridade, uma vez que eles, sem o ensino médio, não conseguem acessar o ensino técnico. Castro (2005, p. 167) mostra que após a reforma as matriculas nos cursos técnicos cresceram $63 \%$ na rede federal e $68 \%$ na rede privada. Sem entrar no mérito da coorte ${ }^{6}$, o autor mostra que após uma certa turbulência os números mostram que houve um salto nas matrículas e que a separação do ensino médio do técnico estava no caminho certo. No entanto, o autor chama a atenção para a dificuldade de identificar essa mudança. $\mathrm{O}$ mesmo diríamos na vigência da atual legislação, pois as frequentes mudanças na forma de registrar o aluno nos censos escolares torna difícil qualquer comparação.

Seguramente não foram os números que moveram a equipe atual do MEC a empreender a vinculação do ensino médio ao ensino técnico. A principal argumentação é de aparência e tem um certo apelo na questão ligada a profissionalização dos jovens, que vivem no velho dilema: não conseguem trabalho porque não têm experiência e, tendo experiência, não conseguem o emprego porque não têm a escolaridade exigida. $\mathrm{O}$ mote foi aliar essas duas dimensões. Mas a questão principal a nosso ver não é o ensino técnico, é o

6. Nos referimos aqui ao termo utilizado pela estatística para definir o movimento de uma determinada população no tempo. 
próprio ensino médio. Dobrar as matrículas do ensino técnico - passar de uma centena para um milhar - não diminui o problema, quando temos $9 \mathrm{mi}-$ lhões de alunos matriculados no ensino médio e cerca de 18 milhões de pessoas entre 18 e 39 anos que já concluíram o ensino médio e não frequentaram nenhuma escola técnica ou de nível superior . Que tipo de impacto terá uma reforma no ensino técnico para cobrir menos de $10 \%$ dos matriculados no ensino médio ${ }^{7}$ ? Importa observar, também, que o grande problema aflige o próprio ensino médio. O que fazer com ele? Essa é uma resposta que não pretendemos dar aqui, mas é a grande questão. O governo FHC buscou promover uma reforma nesse nível de ensino e destinou um recurso similar ao do Proep para que os estados elaborassem e implementassem seus Planos de Reforma do Ensino Médio. Dentre outras coisas, pretendia-se que esse nível educacional desenvolvesse no alunado competências gerais requeridas pelo mundo do trabalho, de tal sorte que ele deixasse de ser um simples elo entre a educação fundamental e o ensino superior e pudesse, inclusive, ter uma parte de sua carga horária aproveitada em cursos técnicos ou tecnológicos. Essas mudanças não chegaram a se concretizar. As próprias diretrizes curriculares do ensino médio não chegaram às salas de aula. No governo Lula, a tentativa de dar um novo rumo e significado ao ensino médio repousa, principalmente, na reedição dos cursos técnicos integrados e na criação do Proeja - Educação de Jovens e Adultos de nível médio integrada à Educação Profissional de nível técnico.

De toda sorte, o que se tem observado, através dos censos escolares, é que as matrículas no ensino médio vêm caindo. Em que pese a intenção dos órgãos de educação em ampliar, significativamente, o ingresso de alunos(as) nesse nível de ensino, os dados têm revelado a falta de atratividade. A questão do ensino médio é fundamental, pois a própria LDB determina que ele é a última etapa da educação básica. A proposta lançada pelo atual governo e denominada de ensino médio inovador ainda não revelou o seu alcance para enfrentar o problema apresentado.

7. Os ministros Fernando Haddad, da Educação e Mangabeira Unger, dos Assuntos Estratégicos, manifestaram na Folha de S. Paulo, em 18 de fevereiro de 2008, opinião em artigo: Ensino público de qualidade. Nele enfatizam o desejo de, a partir da ampliação da Rede Federal, mudar o ensino médio via efeito demonstração. 


\section{Identificação do perfil do alunado da educação profissional de nível médio}

Os dados a seguir não negam a tendência observada no caso do Centro Paula Sousa, citado por nós; somente em algumas áreas estaria havendo um rejuvenescimento das matrículas do ensino técnico a partir do novo marco legal na educação profissional. Evidente que os dados têm de ser tomados com uma certa cautela, pois no momento da sua coleta a junção estava completando um ano de implementação e, como observado, a coleta de dados é de responsabilidade do estabelecimento e se supõe que há dupla contagem nos registros.

De acordo com o censo escolar de 2006 do Inep, 51\% das matrículas em educação profissional de nível médio, em nível nacional, foram nos cursos técnicos na modalidade subsequente, $41 \%$ na concomitante e, apenas, $8 \%$ na modalidade de currículo integrado com o ensino médio. Com pequenas variações, essa realidade se repete em todas as regiões do país, exceto na Sudeste, onde os cursos na modalidade concomitante são os mais encontrados, conforme demonstrado no quadro a seguir, e guardam relação com aquilo que afirmamos no caso do Centro Paula Sousa. A tendência se repete em 2006 e 2007. Os dados também mostram pequena alteração nesses dois anos na educação profissional integrada ao ensino médio. Os dados de 2008 divulgados recentemente não permitem ainda separar as modalidades da oferta da educação profissional.

Quadro 1. Matrículas na educação profissional por modalidade de oferta - 2006

\begin{tabular}{|l|l|l|l|l|l|l|l|}
\hline $\begin{array}{l}\text { Brasil e } \\
\text { Regiões }\end{array}$ & Total & Concomitante & $\%$ & Subsequente & $\%$ & Integrado & $\%$ \\
\hline Norte & 33.572 & 11.231 & $33 \%$ & 18.131 & $54 \%$ & 4.210 & $13 \%$ \\
\hline Nordeste & 110.329 & 28.101 & $25 \%$ & 66.379 & $60 \%$ & 15.849 & $14 \%$ \\
\hline Sudeste & 453.603 & 230.016 & $51 \%$ & 201.464 & $44 \%$ & 22.123 & $5 \%$ \\
\hline Sul & 178.928 & 53.575 & $30 \%$ & 106.859 & $60 \%$ & 18.494 & $10 \%$ \\
\hline $\begin{array}{l}\text { Centro- } \\
\text { Oeste }\end{array}$ & 30.066 & 9.680 & $32 \%$ & 19.254 & $64 \%$ & 1.132 & $4 \%$ \\
\hline Brasil & 806.498 & 332.603 & $41 \%$ & 412.087 & $51 \%$ & 61.808 & $8 \%$ \\
\hline
\end{tabular}

Fonte: Inep, 2006. 
Quadro 2. Matrículas na educação profissional por modalidade de oferta - 2007

\begin{tabular}{|l|l|l|l|l|l|l|l|}
\hline $\begin{array}{l}\text { Brasil e } \\
\text { Regiões }\end{array}$ & Total & Concomitante & $\%$ & Subsequente & $\%$ & Integrado & $\%$ \\
\hline Norte & 30.637 & 3.824 & $12 \%$ & 20.802 & $68 \%$ & 6.011 & $20 \%$ \\
\hline Nordeste & 99.048 & 21.645 & $22 \%$ & 50.659 & $51 \%$ & 26.744 & $27 \%$ \\
\hline Sudeste & 441.863 & 227.173 & $51 \%$ & 185.698 & $42 \%$ & 28.992 & $7 \%$ \\
\hline Sul & 169.266 & 49.686 & $29 \%$ & 97.307 & $57 \%$ & 22.273 & $13 \%$ \\
\hline $\begin{array}{l}\text { Centro- } \\
\text { Oeste }\end{array}$ & 28.719 & 9.541 & $33 \%$ & 17.189 & $60 \%$ & 1.989 & $7 \%$ \\
\hline Brasil & 769.533 & 311.869 & $41 \%$ & 371.655 & $48 \%$ & 86.009 & $11 \%$ \\
\hline
\end{tabular}

Fonte: Inep, 2007.

No Brasil, como um todo, tanto na modalidade concomitante, como na subsequente, a maioria dos(as) alunos(as) dos cursos técnicos em 2006 possuía entre 20 e 39 anos de idade, representando $66 \%$ do universo, contra $44 \%$ dos alunos(as) entre 15 e 19 anos. Em nível estadual a situação se repete. Essa mesma tendência foi observada em 2007, com uma ligeira diminuição para $64 \%$ dessas modalidades em relação ao total. Na maioria dos estados, a população entre 20 e 39 anos representa mais de $70 \%$ do universo de alunos das duas modalidades citadas, merecendo destaque o Acre, onde $100 \%$ do alunado dos cursos concomitantes e $97 \%$ dos subsequentes possuem entre 20 e 39 anos, e o Rio de Janeiro - o único estado que apresenta uma realidade inversa nos cursos concomitantes, com $80 \%$ dos alunos(as) na faixa entre 15 e 19 anos.

\section{Caracterização e cobertura da demanda da educação profissional de nível médio}

De acordo com os dados até o momento apresentados, a educação profissional de nível médio no Brasil está quase que inteiramente baseada na oferta de cursos técnicos nas modalidades concomitante e subsequente ao ensino médio e a maioria do alunado é composta por pessoas com idade variando entre 15 e 39 anos. Para efeito deste estudo, dividimos essa população em duas faixas de idade, quais sejam: de 15 a 19 anos - por ser considerada, no limite, a faixa adequada ao início e conclusão do ensino médio - e 20 a 39 anos. Por essa razão, com vistas a dimensionar a demanda e mensurar os níveis de atendimento, foram levantados dados sobre as parcelas da população, nessas faixas etárias, que estão cursando e as que concluíram o ensino médio e não frequentam escola, que seriam a clientela dos cursos técnicos nas modalidades concomitante, e subsequente, respectivamente. 
Utilizamos para tanto os dados relativos ao Censo Escolar de 2006, e estes foram cotejados com os dados da PNAD de 2006. O cruzamento dos dados tem como resultado o atendimento ocorrido nessas modalidades, em 2006, e os níveis de cobertura e os déficits de atendimento da demanda no país, nas regiões e unidades da federação. Atualmente, em nível nacional, existem mais de 18 milhões de pessoas entre 15 e 39 anos que concluíram o ensino médio e estão fora da escola. Essas pessoas constituem-se em demanda potencial para os cursos técnicos na modalidade subsequente.

Em 2006, na modalidade subsequente de cursos técnicos e na faixa etária de 15 a 39 anos foram matriculados(as) 387.256 alunos(as), número que representa uma cobertura de apenas $2 \%$ da demanda potencial, em nível nacional. A região Sul é a que apresenta o maior percentual de atendimento $(3,79 \%)$. Dentre as unidades da federação, o Rio Grande do Sul é o estado com melhor nível de cobertura de demanda, em torno de $5 \%$, e os estados do Maranhão, Pará e Rondônia os que apresentam os mais baixos índices, em torno de $0.50 \%$, conforme é possível observar no quadro a seguir. A pretensão aqui foi a de mostrar a dimensão de pessoas que potencialmente poderiam seguir para um itinerário formativo em algum dos eixos tecnológicos definidos pelo advento do Catálogo Nacional dos Cursos Técnicos de Nível Médio, Parecer CNE/CEB No. 11/ 2008 (Diário Oficial da União de 07 / 07/2008).

Quadro 3. Cobertura da demanda de cursos técnicos na modalidade subsequente. Pessoas que concluíram o ensino médio

\begin{tabular}{|l|c|c|c|c|c|c|c|c|c|}
\hline & \multicolumn{2}{|c|}{15 a 19 anos } & \multirow{2}{*}{$\%$} & \multicolumn{2}{|c|}{20 a 39 anos } & \multirow{2}{*}{$\%$} & \multicolumn{2}{|c|}{ Total } & \multirow{2}{*}{$\%$} \\
\cline { 1 - 1 } $\begin{array}{l}\text { Brasil - } \\
\text { Região - UF }\end{array}$ & Demanda & Cobertura & & Demanda & Cobertura & & Demanda & Cobertura & \\
\hline Brasil & 1.589 .071 & 95.776 & $6,03 \%$ & 16.919 .496 & 285.500 & $1,69 \%$ & 18.508 .567 & 381.256 & $2,06 \%$ \\
\hline Norte & 90.204 & 2.894 & $3,21 \%$ & 1.358 .074 & 13.882 & $1,02 \%$ & 1.448 .278 & 16.776 & $1,16 \%$ \\
\hline Rondônia & 14.229 & 44 & $0,31 \%$ & 122.658 & 694 & $0,57 \%$ & 136.887 & 738 & $0,54 \%$ \\
\hline Acre & 3.886 & 27 & $0,69 \%$ & 47.732 & 974 & $2,04 \%$ & 51.618 & 1.001 & $1,94 \%$ \\
\hline Amazonas & 23.624 & 1.336 & $5,66 \%$ & 407.268 & 7.018 & $1,72 \%$ & 430.892 & 8.354 & $1,94 \%$ \\
\hline Roraima & 3.795 & 319 & $8,41 \%$ & 47.517 & 771 & $1,62 \%$ & 51.312 & 1.090 & $2,12 \%$ \\
\hline Pará & 30.068 & 633 & $2,11 \%$ & 552.524 & 2.330 & $0,42 \%$ & 582.592 & 2.963 & $0,51 \%$ \\
\hline Amapá & 4.216 & 193 & $4,58 \%$ & 72.676 & 1.026 & $1,41 \%$ & 76.892 & 1.219 & $1,59 \%$ \\
\hline Tocantins & 10.386 & 342 & $3,29 \%$ & 107.699 & 1.069 & $0,99 \%$ & 118.085 & 1.411 & $1,19 \%$ \\
\hline
\end{tabular}


Quadro 3. Continuação

\begin{tabular}{|c|c|c|c|c|c|c|c|c|c|}
\hline \multirow{2}{*}{\begin{tabular}{|l} 
Faixa Etária \\
Brasil - \\
Região - UF
\end{tabular}} & \multicolumn{2}{|c|}{15 a 19 anos } & \multirow{2}{*}{$\%$} & \multicolumn{2}{|c|}{20 a 39 anos } & \multirow{2}{*}{$\%$} & \multicolumn{2}{|c|}{ Total } & \multirow{2}{*}{$\%$} \\
\hline & Demanda & Cobertura & & Demanda & Cobertura & & Demanda & Cobertura & \\
\hline Nordeste & 262.889 & 11.016 & $4,19 \%$ & 3.787 .613 & 49.247 & $1,30 \%$ & 4.050 .502 & 60.263 & $1,49 \%$ \\
\hline Maranhão & 20.703 & 706 & $3,41 \%$ & 370.190 & 1.258 & $0,34 \%$ & 390.893 & 1.964 & $0,50 \%$ \\
\hline Piauí & 10.313 & 241 & $2,34 \%$ & 153.103 & 1.481 & $0,97 \%$ & 163.416 & 1.722 & $1,05 \%$ \\
\hline Ceará & 55.956 & 1.503 & $2,69 \%$ & 670.094 & 5.536 & $0,83 \%$ & 726.050 & 7.039 & $0,97 \%$ \\
\hline $\begin{array}{l}\text { Rio Gde do } \\
\text { Norte }\end{array}$ & 22.559 & 963 & $4,27 \%$ & 260.819 & 3.117 & $1,20 \%$ & 283.378 & 4.080 & $1,44 \%$ \\
\hline Paraíba & 17.031 & 1.976 & $11,60 \%$ & 203.012 & 4.031 & $1,99 \%$ & 220.043 & 6.007 & $2,73 \%$ \\
\hline Pernambuco & 45.055 & 3.111 & $6,90 \%$ & 665.114 & 21.638 & $3,25 \%$ & 710.169 & 24.749 & $3,48 \%$ \\
\hline Alagoas & 10.041 & 310 & $3,09 \%$ & 155.880 & 2.116 & $1,36 \%$ & 165.921 & 2.426 & $1,46 \%$ \\
\hline Sergipe & 9.357 & 537 & $5,74 \%$ & 144.551 & 1.582 & $1,09 \%$ & 153.908 & 2.119 & $1,38 \%$ \\
\hline Bahia & 71.874 & 1.669 & $2,32 \%$ & 1.164 .850 & 8.488 & $0,73 \%$ & 1.236 .724 & 10.157 & $0,82 \%$ \\
\hline Sudeste & 866.962 & 56.173 & $6,48 \%$ & 8.264 .829 & 131.732 & $1,59 \%$ & 9.131 .791 & 187.905 & $2,06 \%$ \\
\hline $\begin{array}{l}\text { Minas } \\
\text { Gerais }\end{array}$ & 175.666 & 11.420 & $6,50 \%$ & 1.669 .590 & 44.705 & $2,68 \%$ & 1.845 .256 & 56.125 & $3,04 \%$ \\
\hline $\begin{array}{l}\text { Espírito } \\
\text { Santo }\end{array}$ & 30.656 & 1.899 & $6,19 \%$ & 308.416 & 6.920 & $2,24 \%$ & 339.072 & 8.819 & $2,60 \%$ \\
\hline $\begin{array}{l}\text { Rio de } \\
\text { Janeiro }\end{array}$ & 96.777 & 7.522 & $7,77 \%$ & 1.397 .680 & 24.129 & $1,73 \%$ & 1.494 .457 & 31.651 & $2,12 \%$ \\
\hline São Paulo & 563.863 & 35.332 & $6,27 \%$ & 4.889 .143 & 55.978 & $1,14 \%$ & 5.453 .006 & 91.310 & $1,67 \%$ \\
\hline Sul & 259.884 & 23.095 & $8,89 \%$ & 2.353 .709 & 75.833 & $3,22 \%$ & 2.613 .593 & 98.928 & $3,79 \%$ \\
\hline Paraná & 109.767 & 7.043 & $6,42 \%$ & 986.349 & 30.656 & $3,11 \%$ & 1.096 .116 & 37.699 & $3,44 \%$ \\
\hline $\begin{array}{l}\text { Santa } \\
\text { Catarina }\end{array}$ & 57.908 & 5.234 & $9,04 \%$ & 533.864 & 10.599 & $1,99 \%$ & 591.772 & 15.833 & $2,68 \%$ \\
\hline $\begin{array}{l}\text { Rio Grande } \\
\text { do Sul }\end{array}$ & 92.209 & 10.818 & $11,73 \%$ & 833.496 & 34.578 & $4,15 \%$ & 925.705 & 45.396 & $4,90 \%$ \\
\hline
\end{tabular}


Quadro 3. Continuação

\begin{tabular}{|l|c|c|c|c|c|c|c|c|c|}
\hline Faixa Etária & \multicolumn{2}{|c|}{15 a 19 anos } & \multirow{2}{*}{$\%$} & \multicolumn{2}{|c|}{20 a 39 anos } & \multirow{2}{|c|}{ Total } & \multirow{2}{*}{$\%$} \\
\cline { 1 - 1 } $\begin{array}{l}\text { Brasil - } \\
\text { Região - UF }\end{array}$ & Demanda & Cobertura & & Demanda & Cobertura & & Demanda & Cobertura & $\%$ \\
\hline $\begin{array}{l}\text { Centro- } \\
\text { Oeste }\end{array}$ & 109.132 & 2.578 & $2,36 \%$ & 1.155 .271 & 14.806 & $1,28 \%$ & 1.264 .403 & 17.384 & $1,37 \%$ \\
\hline $\begin{array}{l}\text { Mato } \\
\text { Grosso Sul }\end{array}$ & 15.283 & 77 & $0,50 \%$ & 169.060 & 1.356 & $0,80 \%$ & 184.343 & 1.433 & $0,78 \%$ \\
\hline $\begin{array}{l}\text { Mato } \\
\text { Grosso }\end{array}$ & 21.274 & 384 & $1,81 \%$ & 210.764 & 1.665 & $0,79 \%$ & 232.038 & 2.049 & $0,88 \%$ \\
\hline Goiás & 48.566 & 1.272 & $2,62 \%$ & 499.508 & 6.220 & $1,25 \%$ & 548.074 & 7.492 & $1,37 \%$ \\
\hline $\begin{array}{l}\text { Distrito } \\
\text { Federal }\end{array}$ & 24.009 & 845 & $3,52 \%$ & 275.939 & 5.565 & $2,02 \%$ & 299.948 & 6.410 & $2,14 \%$ \\
\hline
\end{tabular}

Fonte: Inep, 2006 e PNAD/IBGE, 2006.

O contingente nacional de pessoas cursando o ensino médio, com idades variando entre 15 e 39 anos, em 2006, era de aproximadamente nove milhões, e se constitui na clientela potencial dos cursos técnicos na modalidade concomitante. Por sua vez, foram matriculados, nos cursos técnicos dessa modalidade e nessa faixa de idade, em 2006, 307.656 pessoas, número que representa uma cobertura de 3,45\% da demanda potencial em nível nacional.

Quadro 4. Cobertura da demanda de cursos técnicos na modalidade subsequente. Pessoas que cursam 0 ensino médio

\begin{tabular}{|c|c|c|c|c|c|c|c|c|c|}
\hline \multirow{2}{*}{$\begin{array}{l}\text { Faixa Etária } \\
\text { Brasil - } \\
\text { Região - UF }\end{array}$} & \multicolumn{2}{|c|}{15 a 19 anos } & \multirow{2}{*}{$\%$} & \multicolumn{2}{|c|}{20 a 39 anos } & \multirow{2}{*}{$\%$} & \multicolumn{2}{|l|}{ Total } & \multirow{2}{*}{$\%$} \\
\hline & Demanda & Cobertura & & Demanda & Cobertura & & Demanda & Cobertura & \\
\hline Brasil & 6.718 .460 & 135.051 & $2,01 \%$ & 2.190 .053 & 172.605 & 7,88\% & 8.908 .513 & 307.656 & $3,45 \%$ \\
\hline Norte & 502.236 & 2.082 & $0,41 \%$ & 257.957 & 7.941 & $3,08 \%$ & 760.193 & 10.023 & $1,32 \%$ \\
\hline Rondônia & 53.249 & 304 & $0,57 \%$ & 15.382 & 831 & $5,40 \%$ & 68.631 & 1.135 & $1,65 \%$ \\
\hline Acre & 27.413 & 0 & $0,00 \%$ & 7.666 & 27 & $0,35 \%$ & 35.079 & 27 & $0,08 \%$ \\
\hline Amazonas & 108.174 & 709 & $0,66 \%$ & 66.603 & 2.031 & $3,05 \%$ & 174.777 & 2.740 & $1,57 \%$ \\
\hline Roraima & 16.274 & 0 & $0,00 \%$ & 4.686 & 0 & $0,00 \%$ & 20.960 & 0 & $0,00 \%$ \\
\hline Pará & 208.952 & 468 & $0,22 \%$ & 128.565 & 2.035 & $1,58 \%$ & 337.517 & 2.503 & $0,74 \%$ \\
\hline Amapá & 32.847 & 195 & $0,59 \%$ & 9.765 & 195 & $2,00 \%$ & 42.612 & 390 & $0,92 \%$ \\
\hline Tocantins & 55.327 & 406 & $0,73 \%$ & 25.290 & 2.822 & $11,16 \%$ & 80.617 & 3.228 & $4,00 \%$ \\
\hline
\end{tabular}


Quadro 4. Continuação

\begin{tabular}{|c|c|c|c|c|c|c|c|c|c|}
\hline \multicolumn{3}{|c|}{ Faixa Etária 15 a 19 anos } & \multirow[b]{2}{*}{$\%$} & \multicolumn{2}{|c|}{20 a 39 anos } & \multirow[b]{2}{*}{$\%$} & \multicolumn{2}{|l|}{ Total } & \multirow{2}{*}{$\%$} \\
\hline $\begin{array}{l}\text { Brasil - } \\
\text { Região - UF }\end{array}$ & Demanda & Cobertura & & Demanda & Cobertura & & Demanda & Cobertura & \\
\hline Brasil & 6.718 .460 & 135.051 & $2,01 \%$ & 2.190 .053 & 172.605 & $7,88 \%$ & 8.908 .513 & 307.656 & $3,45 \%$ \\
\hline Nordeste & 1.659 .876 & 7.866 & $0,47 \%$ & 810.585 & 17.514 & $2,16 \%$ & 2.470 .461 & 25.380 & $1,03 \%$ \\
\hline Maranhão & 220.297 & 928 & $0,42 \%$ & 94.414 & 1.381 & $1,46 \%$ & 314.711 & 2.309 & $0,73 \%$ \\
\hline Piauí & 98.972 & 1.180 & $1,19 \%$ & 55.667 & 1.758 & $3,16 \%$ & 154.639 & 2.938 & $1,90 \%$ \\
\hline Ceará & 313.445 & 760 & $0,24 \%$ & 78.441 & 2.518 & $3,21 \%$ & 391.886 & 3.278 & $0,84 \%$ \\
\hline $\begin{array}{l}\text { Rio Gde } \\
\text { Norte }\end{array}$ & 92.113 & 197 & $0,21 \%$ & 39.003 & 196 & $0,50 \%$ & 131.116 & 393 & $0,30 \%$ \\
\hline Paraíba & 102.194 & 800 & $0,78 \%$ & 62.151 & 1.590 & $2,56 \%$ & 164.345 & 2.390 & $1,45 \%$ \\
\hline Pernambuco & 247.743 & 1.915 & $0,77 \%$ & 132.884 & 1.872 & $1,41 \%$ & 380.627 & 3.787 & $0,99 \%$ \\
\hline Alagoas & 79.367 & 457 & $0,58 \%$ & 42.077 & 3.570 & $8,48 \%$ & 121.444 & 4.027 & $3,32 \%$ \\
\hline Sergipe & 57.887 & 290 & $0,50 \%$ & 28.082 & 1.047 & $3,73 \%$ & 85.969 & 1.337 & $1,56 \%$ \\
\hline Bahia & 447.858 & 1.339 & $0,30 \%$ & 277.866 & 3.582 & $1,29 \%$ & 725.724 & 4.921 & $0,68 \%$ \\
\hline Sudeste & 3.068 .406 & 98.243 & $3,20 \%$ & 753.392 & 115.126 & $15,28 \%$ & 3.821 .798 & 213.369 & $5,58 \%$ \\
\hline M inas Gerais & 763.784 & 12.929 & $1,69 \%$ & 174.815 & 13.010 & $7,44 \%$ & 38.599 & 25.939 & $2,76 \%$ \\
\hline $\begin{array}{l}\text { Espírito } \\
\text { Santo }\end{array}$ & 125.882 & 2.050 & $1,63 \%$ & 57 & 73 & $7,73 \%$ & 39 & 4.923 & $02 \%$ \\
\hline \begin{tabular}{|l|} 
Rio de \\
Janeiro
\end{tabular} & 521.820 & 35.458 & $6,80 \%$ & 207.983 & 8.982 & $4,32 \%$ & 729.803 & 44.440 & $6,09 \%$ \\
\hline São Paulo & 1.656 .920 & 47.806 & $2,89 \%$ & 333.437 & 90.261 & $27,07 \%$ & 1.990 .357 & 138.067 & $6,94 \%$ \\
\hline Sul & 992.324 & 23.743 & $2,39 \%$ & 215.491 & 26.722 & $17,51 \%$ & 1.207 .815 & 50.465 & $4,18 \%$ \\
\hline Paraná & 370.344 & 2.033 & $0,55 \%$ & 88.128 & 3.937 & $17,17 \%$ & 458.472 & 5.970 & $1,30 \%$ \\
\hline $\begin{array}{l}\text { Santa } \\
\text { Catarina }\end{array}$ & 261.141 & 7.863 & $3,01 \%$ & 57.322 & 8.612 & $25,95 \%$ & 318.463 & 16.475 & $5,17 \%$ \\
\hline $\begin{array}{l}\text { Rio Gde } \\
\text { do Sul }\end{array}$ & 360.839 & 13.847 & $3,84 \%$ & 70.041 & 14.173 & $20,53 \%$ & 430.880 & 28.020 & $6,50 \%$ \\
\hline $\begin{array}{l}\text { Centro- } \\
\text { Oeste }\end{array}$ & 495.618 & 3.117 & $0,63 \%$ & 152.628 & 5.302 & $3,47 \%$ & 648.246 & 8.419 & $1,30 \%$ \\
\hline $\begin{array}{l}\text { M to } \\
\text { Grosso Sul }\end{array}$ & 78.559 & 723 & $0,92 \%$ & 22.923 & 1.729 & $7,54 \%$ & 101.482 & 2.452 & $2,42 \%$ \\
\hline $\begin{array}{l}\text { Mato } \\
\text { Grosso }\end{array}$ & 109.892 & 454 & $0,41 \%$ & 33.192 & 1.221 & $3,68 \%$ & 143.084 & 1.675 & $1,17 \%$ \\
\hline Goiás & 207.439 & 1.220 & $0,59 \%$ & 69.034 & 1.584 & $2,29 \%$ & 276.473 & 2.804 & $1,01 \%$ \\
\hline $\begin{array}{l}\text { Distrito } \\
\text { Federal } \\
\end{array}$ & 99.728 & 720 & $0,72 \%$ & 27.479 & 768 & $2,79 \%$ & 127.207 & 1.488 & $1,17 \%$ \\
\hline
\end{tabular}

Fonte: Inep, 2006. 
Em nível regional, a região Sudeste é a que apresenta o maior índice de atendimento de demanda (em torno de $6 \%$ ), e a região Nordeste o pior (1\%). Entre as unidades da federação, São Paulo é o estado com melhor desempenho de atendimento em cursos concomitantes, com um índice em torno de $6 \%$, e Roraima e Acre os que apresentam os índices mais baixos $(0 \%)$ e $(0,08 \%)$, respectivamente.

\section{Abrangência das áreas da educação profissional de nível técnico}

É interessante frisar, por exemplo, que, contrariamente ao que se observara no final da década de 1990, os cursos técnicos ofertados nos dias atuais cobrem todas as áreas profissionais, conforme demonstra o quadro a seguir:

Quadro 5. Matrículas da educação profissional por faixa etária

\begin{tabular}{|c|c|c|c|c|c|}
\hline \multirow{3}{*}{ Área Profissional } & \multicolumn{5}{|c|}{ Matrículas da Educação Profissional/Faixa Etária } \\
\hline & \multirow{2}{*}{ Total } & \multirow{2}{*}{\begin{tabular}{|l}
15 a 19 anos \\
$n$
\end{tabular}} & \multirow[b]{2}{*}{$\%$} & \multirow{2}{*}{\begin{tabular}{|l|}
20 a 39 anos \\
$N$
\end{tabular}} & \multirow[b]{2}{*}{$\%$} \\
\hline & & & & & \\
\hline Total & 707.263 & 229.698 & $32 \%$ & 421.803 & $60 \%$ \\
\hline Agropecuária & 42.837 & 27.873 & $65 \%$ & 13539 & $32 \%$ \\
\hline Artes & 8.190 & 2.590 & $32 \%$ & 3768 & $46 \%$ \\
\hline Comunicação & 4.799 & 3.363 & $70 \%$ & 1326 & $28 \%$ \\
\hline Comércio & 8.225 & 772 & $9 \%$ & 4.976 & $60 \%$ \\
\hline Construção Civil & 13.500 & 4.799 & $36 \%$ & 7696 & $57 \%$ \\
\hline Des. Social e Lazer & 15.462 & 2.417 & $16 \%$ & 10123 & $65 \%$ \\
\hline Design & 7.391 & 2.443 & $33 \%$ & 4208 & $57 \%$ \\
\hline Geomática & 1.379 & 455 & $33 \%$ & 845 & $61 \%$ \\
\hline Gestão & 102.408 & 34.430 & $34 \%$ & 60.448 & $59 \%$ \\
\hline Imagem Pessoal & 1.052 & 78 & $7 \%$ & 751 & $71 \%$ \\
\hline Indústria & 128.153 & 44.685 & $35 \%$ & 77.542 & $61 \%$ \\
\hline Informática & 80.765 & 47.709 & $59 \%$ & 29.533 & $37 \%$ \\
\hline M eio-Ambiente & 10.407 & 2.922 & $28 \%$ & 6544 & $63 \%$ \\
\hline M ineração & 2.112 & 447 & $21 \%$ & 1375 & $65 \%$ \\
\hline Química & 24.970 & 7.999 & $32 \%$ & 15915 & $64 \%$ \\
\hline Recursos Pesqueiros & 114 & 56 & $49 \%$ & 52 & $46 \%$ \\
\hline Saúde & 233.493 & 37.038 & $16 \%$ & 172.232 & $74 \%$ \\
\hline Telecomunicações & 9.190 & 4.159 & $45 \%$ & 4763 & $52 \%$ \\
\hline Transportes & 1.581 & 582 & $37 \%$ & 915 & $58 \%$ \\
\hline Turismo e Hospitalidade & 11.235 & 4.881 & $43 \%$ & 5252 & $47 \%$ \\
\hline
\end{tabular}

Fonte: MEC/Inep/DEEB - Censo Escolar 2005.

1 - Matrículas nas formas concomitante e subsequente 
Os dados compilados para esse quadro nos permitem afirmar que existe uma relação entre determinadas áreas profissionais e a faixa de idade do alunado. É o caso das áreas de Agropecuária, Comunicação, e Informática, onde existe um predomínio de jovens entre 15 e 19 anos, e as de Saúde, Desenvolvimento Social e Lazer, Comércio, Construção Civil, Mineração, Imagem Pessoal, Química, Telecomunicações e Transportes, onde o predomínio é de pessoas de 20 até 39 anos de idade.

Conforme observado no início do nosso trabalho, os governos de FHC e Lula empreenderam iniciativas no campo da educação profissional em cujo epicentro esteve a discussão entre educação profissional integrada ou não ao ensino médio, forçada ou opcional, se é que poderíamos assim caracterizar. A verdade é que os números não são conclusivos em relação a um e outro período. Os dados agregados do último Censo Escolar, de 2008, mostram que a matrícula voltou ao patamar observado em 2005-2006. O anunciado aumento de $14 \%{ }^{8}$ nada mais é do que a recuperação de matrículas perdidas no momento da implantação do Decreto 5.154/2004. Uma outra questão é a imprecisão dos dados do Censo Escolar. Se tomados individualmente pelas modalidades (integrado, subsequente ou concomitante), os dados das matriculas totalizam valores superiores aos existentes para a educação profissional de forma agregada. Isso demonstra que ao nível dos estabelecimentos existe duplo registro na informação. Seguramente, muitos estabelecimentos informam duplamente registros de matriculas na modalidade concomitante com a integrada. Como o decreto não proibiu essa integração, é de se esperar que haja ainda múltiplas contagens e que somente com o tempo isso seja depurado.

Os dados desagregados do Censo Escolar de 2008 ainda não estão disponíveis, mas é curioso observar que a matrícula que mais cresceu foi a dos estados. Não se sabe ainda quais das formas previstas pela legislação foi a mais intensa. O próprio Ministro da Educação, ao anunciar os dados, disse que "[...] a educação profissional concomitante ao ensino médio teve aumento de 19,6\%. Já a educação profissional subseqüente - oferecida aos estudantes que já concluíram o ensino médio - experimentou aumento de 10,5\% no número de matrículas" ${ }^{\prime \prime}$. O fato é que o estímulo do governo federal a essa modalidade é a inclusão de matrículas no Fundeb, que tem uma remuneração de 30\% a mais do que o ensino médio tradicional, e o Programa Brasil Profissionalizado, que praticamente se iniciou há menos de um ano e cobre apenas 1/10 dos Estados. Nesse sentido, é difícil afirmar, como afirmam as autoridades do MEC, que isso se deve à maior sensibilidade das secretarias estaduais ao

8. Ver a respeito o portal do Inep. Disponível em: <http:/ / www.inep.gov.br/imprensa/noticias/censo/escolar/news09_02.htm>. Acesso em: 2 fev. 2009.

9. Disponível em: $<$ http: / / portal.mec.gov.br/index.php?option=com_content\&task=view\&id=11960>. Acesso em: 2 fev. 2009. 
tema. Inferimos que o estímulo pode estar ocorrendo como mero efeito estatístico na conta do Fundeb, onde as redes estaduais podem estar lançando mais registros nessa modalidade para angariar maior retorno na redistribuição interna dos recursos do fundo.

Embora esteja havendo uma atenção especial à prioridade dada ao incremento dos cursos técnicos na modalidade de currículo integrado, que de 2005 para 2006 tiveram um crescimento de 52\%, o fato é que a sua importância no total das matrículas é diluída pela baixa proporção que ele representa no total. Além de ser uma modalidade de curso cuja manutenção é mais onerosa e, portanto, mais difícil de ser incorporada em grande escala, pelos poderes públicos estaduais.

Quadro 6. Evolução das matrículas em cursos técnicos no Brasil - 2003 a 2008

\begin{tabular}{|l|l|l|}
\hline Ano & Matrículas & Variação em relação ao período anterior \\
\hline 2003 & 589.383 & - \\
\hline 2004 & 676.093 & $15 \%$ \\
\hline 2005 & 747.892 & $11 \%$ \\
\hline 2006 & 806.498 & $8 \%$ \\
\hline 2007 & 693.610 & $-14 \%$ \\
\hline 2008 & 795.459 & $14,68 \%$ \\
\hline
\end{tabular}

Fonte: Censos Escolares Inep/MEC, Dados agregados.

\section{Considerações finais}

Os dados apresentados demonstram, claramente, que a implementação das modalidades: concomitante e subsequente, aliadas à flexibilidade na construção de itinerários, conferida, sobretudo, pela modularização dos currículos, vieram atender as aspirações de uma população que estava sem nenhuma perspectiva de encaminhamento profissional. Em outras palavras, pessoas com idade superior àquela considerada adequada para o ensino regular, que se viam, até há alguns anos atrás, impossibilitadas de obter formação profissional, porque a única alternativa existente eram os cursos técnicos integrados ao ensino médio, seriados e por disciplina.

Esse contingente de pessoas, como já foi demonstrado, é de cerca de 18 milhões de indivíduos - demanda dos cursos subsequentes - e de 9 milhões - demanda potencial dos concomitantes, alunos do ensino médio.

Entretanto, os níveis de cobertura dessa demanda são extremamente baixos, $2 \%$ e 3,5\% respectivamente, indicando ao poder público a necessidade 
de criar programas e políticas com metas mais audaciosas de atendimento dessas camadas da população, sob pena de se continuar a condenar gerações inteiras a um tipo de inserção no mercado de trabalho, quando ela ocorre, muito aquém de suas possibilidades, necessidades e aspirações.

Além disso, a oferta da educação profissional ainda é notadamente privada, como mostram os dados do Censo Escolar de 2008. Enquanto a rede federal responde por 9,7\% (77.074 matrículas), a rede estadual detém 32,4\% (257.543 matrículas) e a rede privada 54,3\% (431.651 matrículas) de um total de 795.459 matrículas nessa modalidade de ensino. Nesse sentido, o desafio é o de acompanhar nos próximos anos como irá ocorrer essa expansão na oferta. É notório que as escolas da rede federal são em geral de qualidade incomparável, pelo menos por dois motivos: têm uma fonte de recursos assegurada e contam com um nível de alunos com seleção de ingresso altamente competitiva, o que a torna referência em nível nacional. No entanto, se os dados da oferta dessa rede forem cotejados com as matrículas do ensino médio, não chegam a atingir $1 \%$ da população matriculada.

A questão que nos parece crucial neste momento é que ensino médio teremos ou queremos. O Brasil é um dos únicos países do Mundo em que o ensino médio é único. Seguramente não será com o efeito demonstração que $1 \%$ das matrículas vão conseguir inverter as $99 \%$. O desafio é o de repensar o ensino médio dando ao aluno perspectivas de não ser ele uma passagem obrigatória para o acesso a uma profissionalização de nível superior, mas que o ensino médio possa ser de fato uma etapa da vida que proporcione aos jovens meios de convivência com o trabalho e com a descoberta dos valores humanos e científicos.

\section{Referências}

BRASIL. Instituto Nacional de Estudos e Pesquisas Educacionais Anísio Teixeira. Educação profissional técnica de nível médio no censo escolar. Brasília: Instituto Nacional de Estudos e Pesquisas Educacionais Anísio Teixeira, 2006. 59 p.

CARVALHO, Olgamir Francisco de. Educação e formação profissional - trabalho e tempo livre. Brasília: Plano, 2003.

CASTIONI, Remi. A trajetória das políticas de educação profissional voltadas ao mercado de trabalho na última década". In: NOZAKI, Izumi (Org.). Educação e trabalho: trabalhar, aprender, saber. Campinas-SP: Mercado de Letras; Cuiabá-MT: UFMT. Seminário Educação. 2008.

CASTRO, Cláudio de Moura. Os Community Colleges: uma solução viável para o Brasil? In: BID. Unidad de Educacion. Departamento de Desenvolvimento Sustentavel. 
Washington: Banco Interamericano de Desenvolvimento - BID. Notas da Unidade de Educación, dez. 1999.

CASTRO, Cláudio de Moura. O secundário: esquecido em um desvão do ensino?. Brasília: MEC, Inep, 1997 (Série Documental. Textos para discussão).

CASTRO, Cláudio de Moura; GARCÍA, Norma M. El modelo de instituto técnico superior norteamericano - lecciones para América Latina. Washington-DC: BID, 2003.

CASTRO, Cláudio de Moura. Educação técnica: a crônica de um casamento turbulento. In: SCHWARTZMAN, Simon; BROCK, Colin (Org.). Os desafios da educação no brasil. Rio de Janeiro: Nova Fronteira, 2005. p. 153-180.

CHRISTOPHE, Micheline. A legislação sobre a educação tecnológica no quadro da educação profissional brasileira. IETS: Rio de Janeiro. [on-line]. 2005. Disponível em: <http:/ / www.iets.org.br/article.php3?id_article=425>, 24 p., Acesso em: 2 fev. 2009.

CUNHA, Luiz Antônio. Os Ministérios da Educação e do Trabalho na Educação Profissional. In: YANNOULAS, Silva C. Atuais Tendências na Educação Profissional. Projeto: Formação de Gestores e Formadores em Políticas Públicas de Trabalho e Renda: construindo a nova cidadania. Brasília: Convênio MRE-ABC/MTE-SPPE / Flacso. CDROM. 2000 (Coleção Políticas Públicas de Trabalho, Emprego e Geração de Renda).

FERRETI, Celso João. A formação profissional e reforma do ensino técnico no Brasil: anos 90. Educação e Sociedade. Campinas-SP: Cedes, v. 18, n. 59, p. 225-269, ago. 1997. FRIGOTTO, Gaudêncio. Estrutura e organização da educação profissional. In: SEMINÁRIO EDUCAÇÃO PROFISSIONAL - concepções, experiências, problemas e propostas. Anais... Brasília: MEC, Semtec, Proep, 2003. p. 118-119.

FRIGOTTO, Gaudêncio; CIAVATTA, Maria. A busca de articulação entre trabalho, ciência e cultura no ensino médio. In: FRIGOTTO, Gaudêncio; CIAVATTA, Maria (Org.). Ensino médio: ciência, cultura e trabalho. Brasilia: MEC/Semtec, 2004.

FRIGOTTO, Gaudêncio; CIAVATTA, Maria; RAMOS, Marise. A política de educação profissional no governo Lula: um percurso histórico controvertido. Educação e Sociedade. Campinas-SP: Cedes, v. 26, n. 92, p. 1.087-1.113, Especial - out. 2005.

KUENZER, Acácia Zeneida. Ensino médio e profissional: as políticas do estado neoliberal. São Paulo: Cortez, v. 63, 1997 (Coleção Questões da Nossa Época).

LIMA FILHO, Domingos Leite. A desescolarização da escola: impactos da reforma da educação profissional (período 1995 a 2002). Curitiba: Torre de Papel, 2003.

MARQUES, Rosa Maria; MENDES, Aquilas. O gasto federal em educação. In: FALEIROS, Vicente de Paula; NUNES, Selene Peres; FLEURY, Sônia et al. (Org.). A era FHC e o governo Lula: transição? Brasília: Inesc, 2004. p. ?

REZENDE, Fernando; TAFNER, Paulo (Org.). Brasil: o estado de uma nação. Brasília: Ipea, 2006. Vol. 3, p. 121. (Coleção Educação no Brasil: Atrasos, Conquistas e Desafios). ZIBAS, Dagmar Maria Leopoldi; AGUIAR, Márcia Ângela da Silva; BUENO, Maria Sylvia Simões (Org.). O ensino médio e a reforma da educação básica. Brasília: Plano, 2002. 


\section{Changes of the institutional framework of professional education: a look based on the data of the School Census \\ Abstract}

This article discusses the impact of the changes introduced in the legal framework of professional education, particularly with the advent of the Decree no. 5.154/2004 in terms of place offerings by the federal schools, state and private. The objective is to follow up on the behavior of the data of the School Census and analyze if there may be an increase in the openings of this kind of education or if this is merely the effect of an accommodation on the part of the schools, in observance to what the legal orientation prescribes. It is inferred also that a possible amplification of offerings may be occurring by sheer statistical effect. Lastly, the perspectives of secondary education are discussed, a fragile link between the end of basic education and higher education. Keywords: Professional education. School census. Integrated secondary education. Federal system.

\section{Les changements du référentiel institutionnel de l'éducation professionnelle: une lecture à partir des données du Recensement Éducationnel}

\section{Résumé}

Ce travail discute l'impacte des changements introduits dans le référentiel légal de l'éducation professionnelle, en particulier depuis le Décret no. 5.154/2004 déterminant l'offerte de places par les réseaux fédéral, étatique et privé. L'objectif est de suivre le comportement des données du Recensement Scolaire et analyser s'il y aurait une augmentation de l'offerte de cette modalité d'enseignement ou si cela consiste seulement de l'accommodation des systèmes, en observance à ce que prévoit le marque légal. L'on infère aussi qu'une possible ampliation de l'offerte peut être un simple effet statistique. Enfin, l'on discute les chemins de l'enseignement secondaire, un lien fragile entre la fin de l'enseignement primaire et l'enseignement supérieur. Mots clefs : Éducation professionnelle. Recensement scolaire. Enseignement secondaire intégré. Réseau fédéral.

\section{Cambios del marco institucional de la educación profesional: una lectura a partir de los datos del censo escolar Resumen}

Ese trabajo discute el impacto de los cambios introducidos en el marco legal de la educación profesional, particularmente con el adviento del decreto n ${ }^{\circ} 5.154$ / 2004 en términos de oferta de vacantes por las redes federal, estadual y particular. El objetivo es seguir el comportamiento de los datos del censo escolar y analizar si estaría habiendo un aumento en la oferta de esa modalidad de enseñanza o si eso es mero efecto de acomodación de las redes, observando lo que preceptúa el marco legal. Se infiere también que una posible ampliación de ofertas puede estar ocurriendo por mero efecto estadístico. Por fin, se discuten los rumbos de la enseñanza secundaria, eslabón frágil entre el final de la enseñanza primaria y la enseñanza superior.

Palabras clave: Educación profesional. Censo escolar. Enseñanza secundaria integrada. Red federal. 